\title{
Analysis of Hardness, Quality and Fluidity Al-Si Casting Result by Using Clamshell (Placuna placenta) as The Mixture of Sand Moulding
}

\author{
Shikh Mohd Shahrul Nizan Shikh Zahari ${ }^{1}$, Saif Aziz Saputra ${ }^{2,4}$, and Putut Murdanto ${ }^{2}$ \\ ${ }^{1}$ Industrial Chemical Technology Program, Faculty of Science and Technology, Universiti Sains Islam Malaysia \\ ${ }^{2}$ Department of Mechanical Engineering, Faculty of Engineering, Universitas Negeri Malang \\ ${ }^{3}$ Bachelor Program, Mechanical Engineering Department, Universitas Negeri Malang \\ *putut.murdanto.ft@um.ac.id
}

\section{ABSTRACT}

Metal is an element that cannot be separated from human life. Almost all of human activities includes metal element in it. Metals can be formed through several ways, one of which is metal casting. Metal casting is one of technique in producing products where the metal was melted in crucible and then poured in a moulding which is similar to the original shape of the product. Moulding that are commonly used are sand moulding. Commonly, binder which used in sand casting process is bentonite. Bentonite, was kind of mineral which can be run out during its usage. This study aimed to analyse the alternative binder to reduce the usage of bentonite. This study analysed the using of clamshell as the mixture of moulding sand against the hardness, quality and fluidity of Al-Si casting result. The highest hardness value was found at the specimen with the mixture of $11 \%$ clamshells with an average hardness value of $122.96 \mathrm{HV}$. The highest value of fluidity also presented in the specimen which used mixture of $11 \%$ clamshells that resulted the length of specimen at $789 \mathrm{~mm}$. Based on the analysis of casting defect showed that specimen which used $5 \%$ clamshells had the fewest and the smallest defect compared the other specimens.

Copyright (C) 2018Journal of Mechanical Engineering Science and Technology

All rights reserved

Keywords: Clamshells, mixed materials, hardness, quality, and fluidity.

\section{Introduction}

Metal is an element that can not be separated from human life. Almost all of human activities are always include metal element in it. Metal can be formed in several ways, one of which is metal casting. Metal casting is one of technique in making product where the metal melted in crucible then placed in a moulding which is similar to the original shape of product. The technique in metal casting is one of method that is able to apply the knowledge and skill about metal into a useful product, through the recomposition of the various metals into an alloy in order to obtain product with the desired properties, in which the process of forming the workpiece through the process of metal casting [1].

Metal casting involves two separate activities. The first activity is the manufacture of patterns and prints. While the second activity is controlling the composition of melted metal, pouring and inspection of casting product [2]. Generally, material that used in metal casting is $\mathrm{Al}-\mathrm{Si}$ (aluminumsilicon). In this study, the moulding which used in sand casting using bentonite as binder then will be mixed with the other material, that is clamshells. Nowadays, the use of clamshells is still limited as material for ornaments, cosmetics and animal feed.

Clamshell can be used for a mixture of paving blocks and concrete. Because the clamshells can be utilized as the mixture of paving blocks and concrete [3], it is possible to be used for the mixture of sand moulding as binder. The casting result is also influenced by many factors. The defects in casting product which is often found in aluminum alloy are pinhole, dros, and shrinkage cavities [4]. The quality of metal castings also influenced by the fluidity, if its fluidity is lower, the metal will freeze before filling the cavity which has been created. The flow of molten metal is primarily by the viscosity and the roughness of moulding surface [5] 
The specimen of casting result is characterized by using optical microscope to obtain micro photograph. Microhardness tester was originally only performed for small component, but now, is developed for studying the phase, orientation effect in single crystal, diffusion gradient, symptoms of aging, and so on metallic and ceramic material [6].

The hardness of casting product is something that must be considered in casting process. Hardness is the resistance of material againts plastic deformation in local area and surface of material. Plastic deformation is condition in material which is given force when the microstructure of the material does not return to its original shape (irreversible). There are several ways to do hardness testing, namely: (1) Brinell, (2) Rockwell, (3) Vickers, (4) Knoop [7].

\section{Methodology}

This study used pre-experimental research design using model of the one-shot case study. The control variables in this study are the level of water content at 5\%,2\% bentonite and Al-Si alloys. The first step was preparing the piston waste piston as the base material, then preparing the clamshells in the form of powder. Then create three variations of sand moulding with several composition, they were: (1) $88 \%$ silica sand, $5 \%$ clamshells powder $5 \%$, (2) $85 \%$ silica sand and $8 \%$ clamshells powder, (3) $82 \%$ silica sand and $11 \%$ clamshells powder. Each variation given water and bentonite with concentration of 5\%. Casting moulding that used in this study was using the type of dried moulding with fluidity pattern used was Birmingham pattern [8]. Piston waste was melted in the furnace as much as $4 \mathrm{~kg}$ for 1 hour. The melted piston waste poured into sand moulding that had been mixed with clamshell powder, the cooling process using air media. After that, the measuring of specimen by using steel ruler.

\section{Results and discussion}

\section{A. Hardness Testing}

Hardness testing was conducted by using Micro Vickers hardness tester. The scale which used was HV (Vickers Hardness) with penetration diamond pyramid style, with the load of $300 \mathrm{gf}$ and dwell for 10 seconds [9]. Hardness testing aimed to determine the effect of the clamshell powder on sand moulding against the hardness of Al-Si alloys.

Based on the results of hardness testing in Figure 1, could be seen the hardness level of casting product with variation of $11 \%$ clamshell had the highest hardness value than the others variation with value of $122.96 \mathrm{HV}$. The variation of $8 \%$ clamshell was second rank with hardness value of $110.22 \mathrm{HV}$. While the variation of 5\% clamshells was specimen with the smallest hardness value at $110.18 \mathrm{HV}$. The hardness level of casting results was closely related to the chemical bonding of material [10].

\section{B. Casting Quality Result}

\section{1) Visual observation}

There was defect in every casting process. The defect product consisted of various types and different causes. Many factors caused casting defect [11]. One of them was the permeability of the moulding.

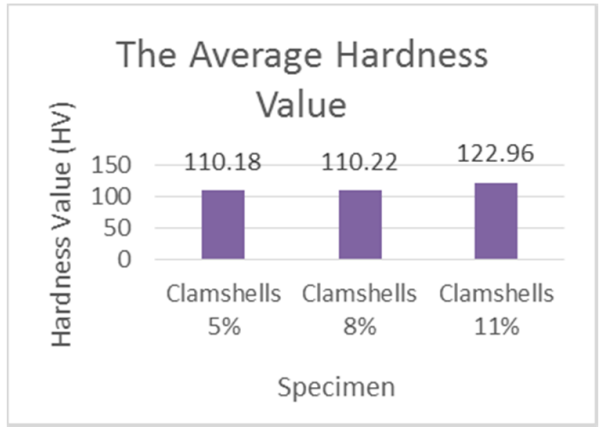

Fig. 1.The Average Hardness Value of Casting Result Againts Clamshells Variations 
According to the casting result in Figure 2, the specimen which using 5\% clamshells had the fewest casting defect compared with other variations. The variation with used $8 \%$ clamshells and $11 \%$ clamshells had the same number of defects. There were a lot of wrong flow, the molten metal did not fill the expected pattern. This could happen due to the cope and drag that did not close tightly, so that there was slight gap which molten metal placed in.

\section{Macrostructure}

Figure 3 showed the macro photos of specimens. Macro photo testing aimed to see the spread of the cast defects on the surface of the specimen.

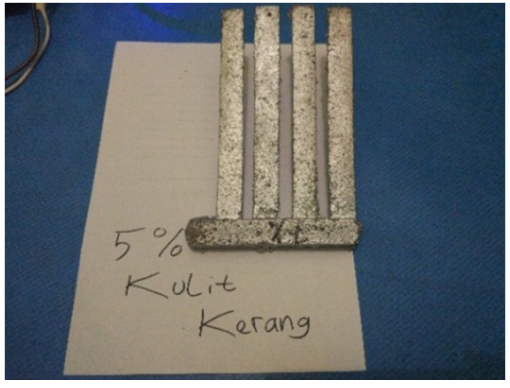

$5 \%$ Clamshells

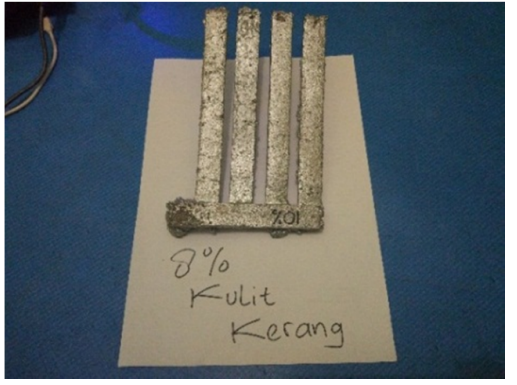

$8 \%$ Clamshells

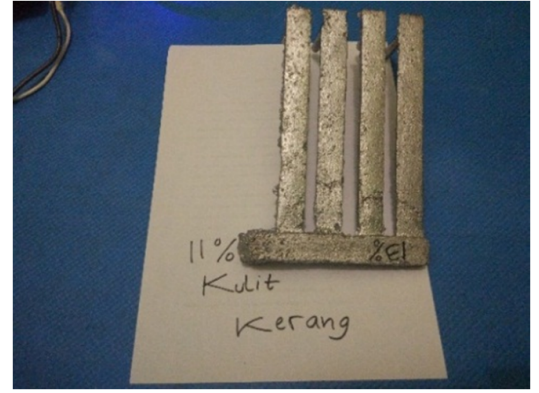

$11 \%$ Clamshells

Fig. 2. The Casting Results of Al-Si Using Clamshell Variation

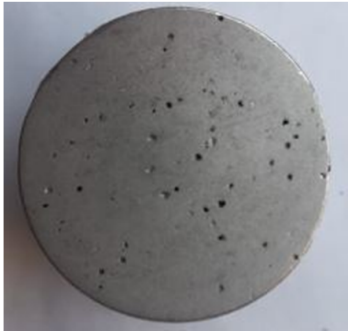

$5 \%$ Clamshells

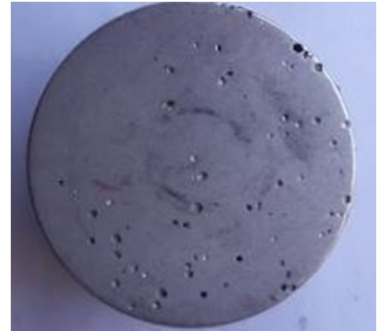

$8 \%$ Clamshells

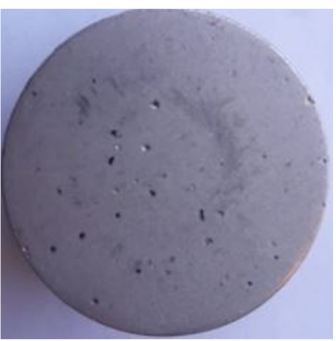

Clamshells $11 \%$

Fig. 3.Macro Photos of Al-Si Surface Using Clamshells Variations 
Based on the results that showed in Figure 4, the specimen with variation of $11 \%$ clamshells had the fewest smallest cast defect when compared with other specimens, there were found \pm 12 pinhole defects and \pm 10 open grain structure defects. The data obtained from macro photos showed that specimens with variation of $5 \%$ clamshells had \pm 33 pinhole defects, and also \pm 22 pieces open grain structure defects, so that the specimen was seen the worst among the other. While specimen with variation of $8 \%$ clamshells had \pm 33 pinhole defects and \pm 18 open grain structure defects.

\section{Microstructure}

Microstructure of Al-Si was taken to understand the matrix of Al-Si that formed and castings defects which was not visible through testing tool micro photograph with magnification up to 881 times.

According to the micro photos that showed at Figure 4, could be understood that variation that used 5\% clamshells was rich of Aluminum (Al) grain or $\mathrm{Al}$ matrix was more dominant than the Silicon ( $\mathrm{Si}$ ) grain. These results were also related to the hardness level of Al-Si alloy, because the variation of 5\% clamshells had the lowest hardness value. The variations with $8 \%$ clamshells was dominated with the matrix of silicon $(\mathrm{Si})$. Aluminum $(\mathrm{Al})$ was also seen as grain boundary of silicon (Si), although it did not look conspicuous. While the variations of $11 \%$ clamshells showed that the deployment of $\mathrm{Si}$ was more evenly, this was also affected its hardness value. Al-Si with this variation had the highest hardness value among others.

\section{E. Fluidity Testing}

Fluidity was the ability of liquid metal to flow into the moulding. The pattern that was used in this study followed the principle of Birmingham that used plates with different thicknesses [12], [13]. Fluidity test was conducting by observing at the size of casting product. Figure 5 showwd the results of total length of specimen with clamshells variation of 5\%,8\% and $11 \%$.
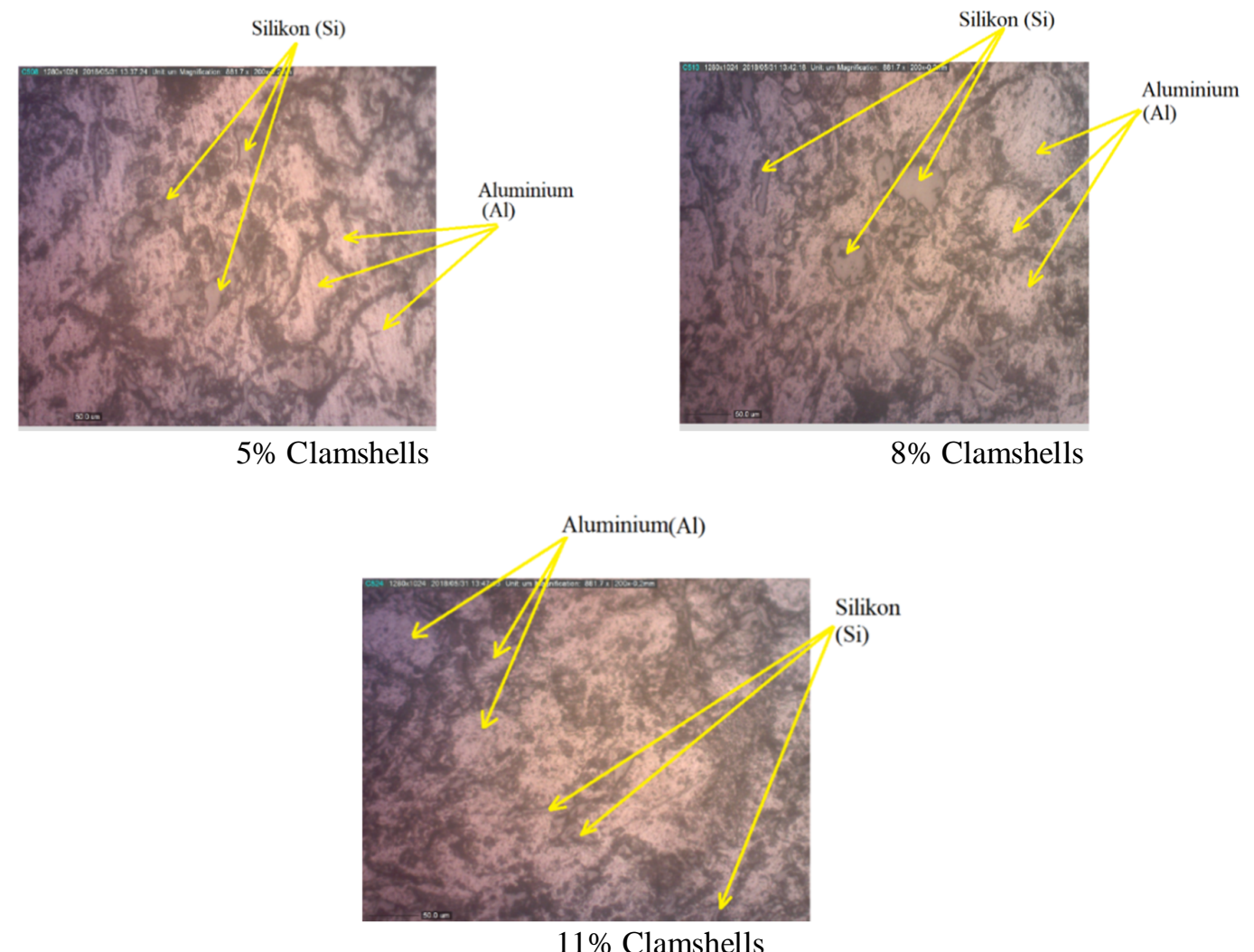

Fig. 4.Microstructure of Al-Si Using Clamshell Variation 


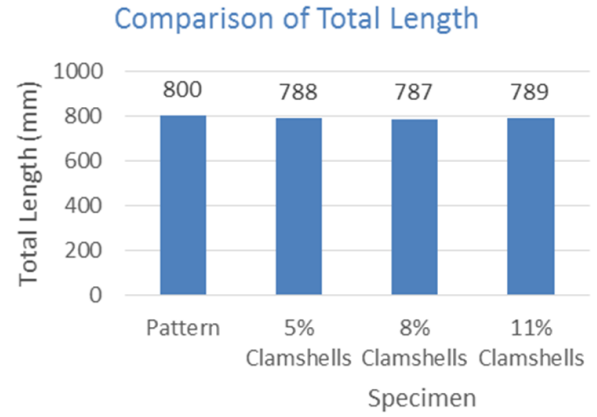

Fig. 5.Comparison of Casting Product Total Length

\section{Conclusion}

According to hardness testing, the highest average value of hardness was obtained by the specimen with variation of $11 \%$, with the hardness value of $122.96 \mathrm{HV}$. Visual observation of each specimen was found that there were several defects in this casting process such as air cavity, shrinkage, mould loss and wrong flow. The results of macro photos with variation of $11 \%$ clamshell showed that this material had the fewest defect. The highest fluidity was obtained in the specimen with variation of $11 \%$ clamshell that proved by its total length that was $789 \mathrm{~mm}$.

\section{References}

[1] H. Sujana, "Teknik Pengecoran Logam," J. Chem. Inf. Model., vol. 53, no. 9, hal. 1689-1699, 2013.

[2] S. Kalpakjian dan S. R. Schmid, "Manufacturing engineering and technology," Manuf. Eng. Technol., 2014.

[3] E. W. Kusuma, "PAVING BLOCK O 1 e h : O 1 e h :," 2012.

[4] P. Puspitasari dan A. Khafiddin, "Analisis Hasil Pengecoran Logam Al-Si Menggunakan," no. 2, hal. 1$11,2014$.

[5] T. Surdia dan S. Saito, "Pengetahuan Bahan Teknik," hal. 372, 1999.

[6] R. . Smallman dan R. . Bishop, Modern Physical Metallurgy and Materials Engineering. 1999.

[7] M. P. Groover, Fundamentals of modern manufacturing, vol. 53, no. 9. 2013.

[8] F. F. Bownes, "Sand Casting," in Castings, 1971, hal. 63-74.

[9] G. F. Vander Voort dan G. M. Lucas, "Microindentation hardness testing," Adv. Mater. Process., vol. 154, no. 3, hal. 21-25, 1998.

[10]R. J. D. Tilley, "Mechanical properties of solids,” Underst. Solids, hal. 293-336, 2004.

[11]R. Rajkolhe, J. G. Khan, dan A. Professor, "Defects, Causes and Their Remedies in Casting Process: A Review," Int. J. Res. Advent Technol., vol. 2, no. 3, hal. 2321-9637, 2014.

[12] M. Di Sabatino, L. Arnberg, S. Brusethaug, dan D. Apelian, "Fluidity evaluation methods for Al-Mg-Si alloys," Int. J. Cast Met. Res., vol. 19, no. 2, hal. 94-97, 2006.

[13][13]M. K. Joseph, F. Banganayi, dan D. Oyombo, "Moulding Sand Recycling and Reuse in Small Foundries," Procedia Manuf., vol. 7, hal. 86-91, 2017. 